\title{
Analysis of Physical Phenomena and Changes in Thermal and Structural Properties of Polymer Materials after Ageing in Natural Conditions
}

\author{
A. KALWIK* AND P. POSTAWA \\ Department of Technology and Automation, \\ Faculty of Mechanical Engineering and Computer Science, \\ Częstochowa University of Technology, al. Armii Krajowej 19c, 42-200 Częstochowa, Poland \\ Doi: $10.12693 /$ APhysPolA.139.562 \\ *e-mail: aleksandra.kalwik@pcz.pl
}

\begin{abstract}
The paper presents the results of the analysis of physical phenomena accompanying photodegradation processes of the polymers surface layer. During the interaction of ultraviolet radiation, atoms are knocked out of the polymer chains and thus the macromolecules are interrupted, which leads to the imbalancing of structural stability of plastics. The article shows the results of thermal analysis and evaluation of the structure of selected polymeric materials after ageing under natural conditions. The samples produced by injection moulding were aged in the European zone for 10 years. Thermal properties of the reference and degraded samples were tested by thermogravimetric analysis and thermomechanical analysis at dynamically changing loads. By analysing the TGA and DTG curves, the effect of energy of radiation UV on the change of melting enthalpy and mass loss rate of the tested samples was determined.
\end{abstract}

topics: polymeric materials, natural weathering, thermogravimetric analysis

\section{Introduction}

Natural (atmospheric) ageing is defined as a series of changes occuring in a material as a consequence of external factors' influence. Usually this process is initiated by sunlight (photodegradation). Its rate, on the other hand, is enhanced in particular by heat (thermodegradation) [1] as well as downfalls (hydrolytic degradation), air pollution, wind and internal stresses (mechanodegradation) [2]. Ageing under natural conditions is a process which causes a slow destruction of polymeric materials [3], whereby the type and intensity of the entire changes depend, among other things, on the structure of the polymer or the type and intensity of the effect of factors causing changes in polymeric materials $[4,5]$.

An extremely important role in the susceptibility to degradation is played by various types of modifying additives or polymer blends, especially of natural origin, which show lower resistance to environmental factors [6]. The addition of photostabilisers significantly delays the ageing processes under natural, as well as accelerated conditions [7]. In turn, in the case of natural fibre composites, it is extremely important to use the optimum ratio of the chemical additive mixture to achieve a balance between strength and durability requirements [8].
A complete understanding of the influence of atmospheric factors on changes in physical and mechanical properties of polymeric materials along with their correlation is important in terms of predicting the durability of materials. Past studies have shown that degradation of polymeric materials occurs much faster in hot, humid areas during exposure [9-11].

The aim of this study was to determine the effect of atmospheric factors under the conditions of the European zone on the changes in the properties of selected polymeric plastics exposed for a period of 10 years.

\section{Materials and methods}

The following thermoplastic materials were used for comparison: poly(amide) with a $25 \%$ glass fibre content $(\mathrm{PA} 6+25 \mathrm{GF})$ and poly(styrene) (PS). The specimens were made on a KraussMaffei KM65160 C4 injection moulding machine with a mould closing force of $650 \mathrm{kN}$. The obtained mouldings were exposed to atmospheric conditions in special holders set at an angle of $45^{\circ}$. The aged and nonaged samples were comparatively analysed by the dynamic mechanical analysis (DMTA) and the thermogravimetric analysis (TGA). 
The recording of the mass changes of the tested samples with increasing temperature was carried out by the thermogravimetric analysis (TGA) on a Netzsch STA 449 F5 Jupiter device. The analysis under dynamic conditions allows for obtaining curves related to mass loss as a function of temperature. To improve the readability of the TGA curve, the differential thermogravimetric analysis (DTG) is performed, where the DTG curve is the first derivative of the thermogravimetric curve with respect to temperature or time.

The TGA curve is defined as the following function:

$$
G=f(T)
$$

where $G$ - the mass, $T$ - the temperature.

The DTG curve, on the other hand, takes the following form

$$
\frac{\mathrm{d} G}{\mathrm{~d} t}=f(T),
$$

where $\mathrm{t}$ - the time, whereby $T=\beta t$ with $\beta$ - the sample heating rate.

The dynamic mechanical analysis (DMTA) was used to evaluate the behavior of materials at short loading times. They allow evaluating the transformations that take place in polymeric materials in a wide range of temperatures and frequency of load changes. When the sample is subjected to periodically varying (sinusoidal) vibrations, the strain takes the values according to relation

$$
\sigma=\sigma_{0} \sin (\omega t+\delta)
$$

where $\omega$ - the angular frequency, $\delta$ - the phase shift angle, $\sigma_{0}$ — the stress amplitude.

Dynamic mechanical properties were tested using a Netzsch DMA 242 device. The specimens, in the form of beams measuring $56 \times 10 \times 4 \mathrm{~mm}^{3}$, were subjected to three-point free bending of the specimen in a dedicated holder. The obtained results, prepared with the Proteus Analysis software, were presented in the form of graphs of changes of storage modulus $E^{\prime}$ and the angle of mechanical loss $\tan (\delta)$ as a function of temperature changes.

\section{Results}

Table I presents the summary results of the thermogravimetric analysis for the original samples and samples aged under natural conditions. The influence of atmospheric factors on changes in the mass of the tested specimens was determined. Due to the observation of changes of the tested surfaces, only the surface layer of the samples, where the influence of degradation factors and thus the observed changes were the largest, was selected for tests. For the primary samples made of pol(amide), the TGA and DTG curves remain constant until temperature of $252^{\circ} \mathrm{C}$ is reached. Thereafter, a rapid weight loss of about $73 \%$ is observed.

The analysis of the DTG curve shows that the highest rate of mass loss occurs at $452.6^{\circ} \mathrm{C}$. Ageing under natural conditions has shifted the temperature of the fastest mass loss as well as the rapid

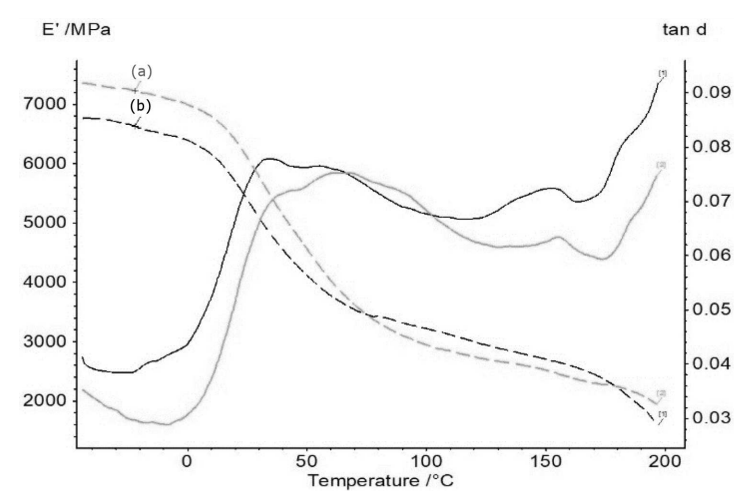

Fig. 1. The course of changes of storage modulus $E^{\prime}$ and angle of mechanical loss $\tan (\delta)$ as a function of temperature changes for original (a) and aged PA (b).

\section{TABLE I}

Thermogravimetric analysis results for original samples and samples aged under natural conditions.

\begin{tabular}{l|c|c|c}
\hline \hline \multicolumn{1}{c|}{ Material } & $\begin{array}{c}\text { Mass } \\
\text { change [\%] }\end{array}$ & $\begin{array}{c}\text { Residual } \\
\text { mass [\%] }\end{array}$ & $\begin{array}{c}\text { DTG } \\
\left.\text { peak [ }{ }^{\circ} \mathrm{C}\right]\end{array}$ \\
\hline PA6+25GF original & 72.91 & 24.45 & 452.6 \\
PA6+25GF 10 years & 71.43 & 27.90 & 440.2 \\
PS original & 99.47 & 0.12 & 428.4 \\
PS 10 years & 89.44 & 10.14 & 411.9
\end{tabular}

mass decrease towards lower values. The higher percentage of residual mass may indicate the loss of a polymeric material on the surface of the aged samples. In turn, in the case of samples made of poly(styrene), the TGA and DTG curves remain constant up to a temperature of about $179^{\circ} \mathrm{C}$ for original samples and about $120^{\circ} \mathrm{C}$ for samples aged under natural conditions. The highest mass loss rate for the original samples occurs at $428.4^{\circ} \mathrm{C}$, while this value is $16.5^{\circ} \mathrm{C}$ lower for the degraded samples. The higher residual mass of the aged samples may indicate the presence of organic compounds, formed under the influence of atmospheric conditions, which did not decompose under the influence of high temperature in the furnace chamber.

The effect of atmospheric conditions on the changes of dynamic mechanical properties for poly(amide) and poly(styrene) at vibration frequency of $1 \mathrm{~Hz}$ is shown in Figs. 1 and 2. The dashed lines indicate the storage modulus and the solid lines - the values of the tangent of the mechanical loss angle.

The ageing of poly(amide) under natural conditions caused a decrease in the value of the storage modulus (Fig. 1) in comparison with the original material. For the non-aged material, the value was $7400 \mathrm{MPa}$, while for the aged material it was $6800 \mathrm{MPa}$. A shift in the temperature at which the maximum occurs in the case of the poly(amide) aged in natural conditions by several 


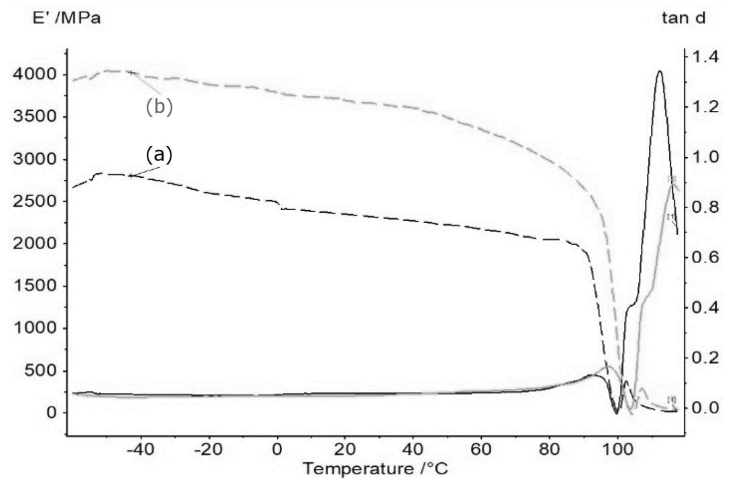

Fig. 2. The course of changes of storage modulus $E^{\prime}$ and angle of mechanical loss $\tan (\delta)$ as a function of temperature changes for original (a) and aged PS (b).

degrees can also be observed. In the temperature range $75 \div 180^{\circ} \mathrm{C}$, it can be observed that the values of the storage modulus after ageing are larger than before as well as there is a smaller difference between the positions of the two curves than at the beginning.

Analysing the course of changes of the mechanical loss angle $\tan (\delta)$, one can notice a similar range of temperatures in which the studied materials show the glass transition transformations. The aged samples are characterized by larger values of the angle in the course of the curve in comparison with the values obtained for the non-aged samples. Near the glass transition temperature, the viscoelastic properties change rapidly with changing temperature. The glass transition is more visible for the original material, not subjected to natural ageing. Atmospheric conditions caused a decrease in stiffness, which may be related to the presence of more glass fibre on the surface as compared to the reference sample.

Figure 2 shows the course of changes of the storage modulus $E^{\prime}$ and the mechanical loss angle $\tan (\delta)$ as a function of temperature for unaged and aged poly(styrene) under natural conditions. It can be seen in the graph that the effect of weathering conditions caused a significant increase in the value of the storage modulus, which indicates an increase in the stiffness of the tested material. For the reference sample, this value was $2830 \mathrm{MPa}$, while for the aged sample it was $4040 \mathrm{MPa}$. In the case of the tangent of the mechanical loss angle, a shift in the temperature, at which the maximum occurs, can be observed.

\section{Conclusions}

The analysis of the obtained results allows concluding that ageing under natural conditions influences the changes of properties of selected polymeric materials to varying degree, depending on their morphology.
Analysing the thermogravimetric curves, one can notice the differences in the values of residual masses as well as in the values of temperatures at the beginning and the end of weight loss and the values of temperatures at which the weight loss is the fastest.

The properties of aged polymeric materials depend largely on their supermolecular structure. Atmospheric factors had influenced the decrease in stiffness of the sample made of poly(amide) and its increase for the sample made of poly(styrene).

\section{References}

[1] J. Xiong, X. Liao, J. Zhu, Z. An, Q. Yang, Y. Huang, G. Li, Polym. Degrad. Stab. 146, 212 (2017).

[2] C. Badji, J. Beigbeder, H. Garay, A. Bergeret, J.-C. Bénézet, V. Desauziers, Polym. Degrad. Stab. 148, 104 (2018).

[3] P. Srimalanon, W. Yamsaengsung, A. Kositchaiyong, E. Wimolmala, K. Isarangkura, N. Sombatsompop, EXPRESS Polym. Lett. 10, 289 (2016).

[4] S.M. Al-Salem, J. Environ. Manage 230, 355 (2019).

[5] D. Sobków, J. Barton, K. Czaja, M. Sudoł, B. Mazoń, Chemik 68, 347 (2014).

[6] L.L. Lizárraga-Laborín, J.M. QuirozCastillo, J.C. Encinas-Encinas, M.M. Castillo-Ortega, S.E Burruel-Ibarra, J. Romero-García, J.A. Torres-Ochoa, D. Cabrera-Germán, D.E. RodríguezFélix, Polym. Degrad. Stab. 155, 43 (2018).

[7] T.V. Nguyena, X.H. Lea, P.H. Daoa, Ch. Deckerc, P. Nguyen-Tri, Prog. Org. Coat. 124, 137 (2018).

[8] Z.N. Azwa, B.F. Yousif, A.C. Manalo, W. Karunasena, Mater. Des. 47, 424 (2013).

[9] Y. Shi, J. Qin, Y. Tao, G. Jie, J. Wang, Polym. Test. 76, 138 (2019).

[10] Y. Lv, Y. Huang, M. Kong, Q. Yang, G. Li, Polym. Test. 64, 65 (2017).

[11] M. Philip, F. Al-Azzawi, J. Polym. Environ. 26, 3139 (2018). 